\title{
Aplikasi Citra Landsat 8 OLI/TIRS Dalam Mengidentifikasi Alterasi Hidrotermal Skala Regional; Studi Kasus Kecamatan Suoh dan Bandar Negeri Suoh
}

\author{
Arsy Nurrochman ${ }^{1 *}$, Rindy Febriani ${ }^{1}$, Vivi Putri Yuliatama ${ }^{1}$ \\ 1Jurusan Teknik Geofisika, Universitas Lampung, Kota Bandar Lampung, Indonesia
}

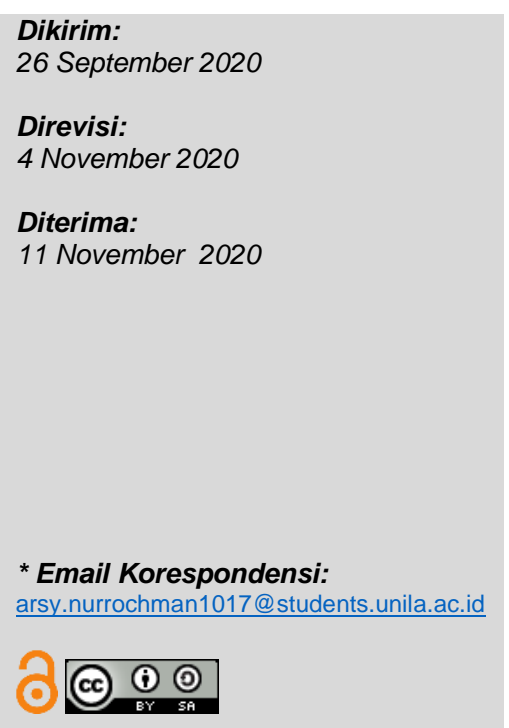

\begin{abstract}
Research has been carried out on geothermal exploration using Remote Sensing. In general, remote sensing is a method used to collect data or information without the need to touch the object to be studied. Remote sensing is done using aerial photographs or using satellite imagery such as Landsat-8, ALOS PALSAR, Radar, and Sentinel. Remote sensing is often used in geothermal exploration because it has the advantage of being able to access remote areas and does not require large costs. This research was conducted using Landsat 8 OLI/ TIRS imagery which aims to map the hydrothermal alteration area regionally with the case study of Suoh, West Lampung. The research was carried out by processing several bands with a pixel range that can represent hydrothermal mineral alteration minerals in the study area. In the research area, the mineral alteration was detected in yelloworange color on composite images 4/2,6/7, 5, and 10, using the density slicing method. From this research, it was found that the area with hydrothermal alteration reaches $223 \mathrm{Ha}$.
\end{abstract}

Keywords: alteration mineral; density slicing; landsat; hydrothermal; remote sensing.

\section{PENDAHULUAN}

Indonesia merupakan daerah kepulauan banyak gunung api aktif, hal ini dikarenakan kondisi geologi Indonesia yang merupakan daerah subduksi. Daerah subduksi tersebut membentang dari pulau Sumatera - Jawa - Bali - hingga NTT. Hal ini mengakibatkan maraknya bencana geologi seperti gempa bumi dan juga erupsi gunung api. Namun, dibalik itu semua, dikarenakan banyaknya Gunung di Indonesia, membuat Indonesia menjadi negara dengan potensi panas bumi terbesar didunia. Hal ini harus kita manfaatkan semaksimal mungkin.. Namun, biasanya daerah geothermal berada pada daerah yang sulit terjangkau sehingga dibutuhkan alternatif lain untuk melihat kondisi daerah tersebut.

Salah satu alternatif yang dapat digunakan ialah dengan melihat potensi geothermal dari persebaran mineral yang telah mengalami alterasi. Hal ini dapat dilakukan tanpa harus pergi ke daerah penelitian, yaitu dengan menggunakan Remote Sensing atau penginderaan jauh.

Secara umum, penginderaan jauh merupakan metode yang dilakukan untuk mengumpulkan data atau informasi tanpa perlu menyentuh objek yang diteliti (Gupta, 2018). Analisis citra andsat umum digunakan untuk mengetahui kondisi permukaan bumi dengan memanfaatkan karakter reflektansi serta absorbsi gelombang elektromagnetik dari objek-objek yang berada di permukaan bumi (Sabins, 1999).

Penginderaan jauh (remote sensing) dapat dilakukan dengan menggunakan citra dari foto udara ataupun citra dari satelit seperti Landsat-8, ALOS PALSAR, Radar, dan Sentinel. Belakangan ini, penginderaan jauh sering di gunakan dalam eksplorasi panas bumi karena dianggap mempunyai banyak keunggulan. Daerah potensi panas bumi sering kali terletak pada daerah yang 
sukar untuk dijangkau sehingga akses ke daerah penelitian akan menghabiskan biaya yang besar. Sehingga analisis menggunakan citra satelit dinilai lebih efektif dilakukan sebagai studi pendahuluan sebelum ke lapangan (Iqbal dan Bella, 2019).

Penginderaan jauh dapat digunakan untuk identifikasi alterasi hidrotermal. Batuan teralterasi merupakan hasil dari reaksi antara fluida panas bumi dengan batuan yang dilewatinya. Terdapat tiga jenis alterasi yaitu pergantian alterasi, pengisian ruang, dan pelarutan batuan (Browne, 1998 dalam Utami, 2015). Keberadaan batuan alterasi menjadi petunjuk penting dalam pembuatan peta potensi panas bumi yang aktif (Browne, 1970).

Pulau Sumatera sendiri merupakan salah satu pulau di Indonesia yang memiliki banyak titik potensi panas bumi yaitu 93 lokasi dengan total potensi sekitar $12 \mathrm{GW}$ (Hochstein dan Sudarman, 2008). Salah satu potensi panas bumi yaitu berada di Suoh-Sekincau yang terletak di Kabupaten Lampung Barat. Titik potensi ini merupakan gabungan dari potensi panas bumi yang ada di Danau Suoh dan Gunung Sekincau dengan estimasi potensi sebesar 400 Mwe. Berdasarkan hasil eksplorasi yang telah dilakukan oleh pusat Sumber Daya, Mineral, Batubara, dan Panas Bumi (PSDMBP), reservoir pada sistem Suoh-Sekincau mempunyai temperature sebesar $>250^{\circ} \mathrm{C}$ sehingga termasuk ke dalam sistem dengan terperature yang tinggi. (PSDMBP, 2017).

Pada penelitian ini memfokuskan pada penginderaan jauh guna mengidentifikasi alterasi hidrotermal menggunakan citra dari foto udara ataupun citra dari satelit seperti Landsat-8, ALOS PALSAR. Sehingga pada penilitian ini dapat menghasilkan data potensi panas bumi pada daerah Suoh dengan baik tanpa harus mengunjungi daerah penelitian.

\section{TINJAUAN PUSTAKA}

Daerah penenlitian terletak pada potensi panas bumi Suoh-Sekincau yang berada di Kabupaten Lampung Barat. Secara morfologi, Danau Suoh dan Gunung Sekincau termasuk wilayah Bukit Barisan Sumatera yaitu Busur Gunung Api berumur TersierKuarter (volcanic arc) yang terbentuk akibat subduksi Lempeng Ind-Australia di bawah Lempeng Eurasia yang dilewati oleh sesar besar Sumatera (great sumatera fault) dengan arah barat laut tenggara. Pada bagian barat daya didominasi oleh kelurusan berarah barat laut tenggara dan merupakan segmen dari sesar besar Sumatera pada segmen Semangko (Barber, 2005). Pada bagian tengah terdapat cekungan yaitu Danau Suoh yang merupakan danau yang terbentuk akibat sesar strike-slip dan membentuk pull-apart basin (Fossen, 2010).

Geologi sepanjang lajur sesar Sumatera segmen Semangko (Ranau-Suoh) terdiri atas tiga unsur pokok dan mendasar, yakni bentang alam, batuan, dan struktur geologi (Soehaimi dkk, 2013). Bentang alam di sepanjang lajur sesar Sumatera segmen Semangko (Ranau-Suoh) ini memiliki ciri khusus berupa lembah bersungai, berawa dan lembang kering, dengan lereng yang curam hingga landai dengan pola jurus memanjang berarah $\mathrm{U} 330^{\circ} \mathrm{T}$ (barat laut - tenggara) (Siregar \& Yudhicara, 2017).

Menurut Soehaimi dkk (2013), batuan dasar penyusun kedua lembah ini adalah pasir tufan berwarna putih bersifat lepas, berbutir kasar hingga halus. Butiran kasar berukuran kerikil terdiri atas fragmen batuan dan pumis. Struktur geologi sekunder dapat dijumpai juga di sepanjang lajur sesar ini berupa sesar mendatar dan sesar normal (turun). Sesar mendatar merupakan perkembangan lajur gerusan sesar utama, sedangkan sesar normal merupakan perkembangan lajur tarikan. Struktur lipatan tidak dapat diamati dengan baik di sepanjang lajur sesar ini karena fisik batuan penyusunnya yang bersifat lepas dan getas, sehingga tidak terjadi sistem lipatan.

Menurut Amin (1993), geologi daerah penelitian terdiri dari beberapa formasi batuan yang diendapkan dari tua ke muda. Formasi yang terdapat pada daerah penelitian yaitu Formasi Hulusimpang yang disusun oleh breksi gunungapilava-tuf, Formasi Seblat yang disusun oleh perselingan batupasir-batulempung-batulanaugampingan. Formasi Simpangur yang disusun oleh batupasir tufan-tuf, Formasi Ranau yang disusun oleh breksi batuapung-tuf, Batuan Gunungapi Kuarter Tua yang disusun oleh lava andesit-basalttuf-breksi gunungapi, dan Batuan Gunungapi Kuarter Muda yang disusun oleh breksi-lava-tuf. Beberapa manifestasi yang keluar di daerah penelitian banyak dijumpai di Danau Suoh yang merupakan kontak antara satuan aluvium dengan produk Gunungapi Kuarter Tua, sedangkan pada daerah Gunung Sekincau, manifestasi banyak dijumpai di sekitar lereng gunung yang merupakan satuan batuan Gunungapi Muda Kuarter Sekincau (lqbal \& Bella, 2019).

\section{DASAR TEORI, BAHAN DAN METODE PENELITIAN}

\subsection{Konsep Dasar}

Dalam penelitian ini menggunakan Metode NDVI dan Density Slicing. Kedua metode tersebut memiliki kegunaannya masing-masing. Metode NDVI memiliki kegunaan untuk melihat kondisi dari vegetasi daerah penelitian, sementara Desnsity Slicing mempunyai fungsi untuk memetakan mineral-mineral tertentu di daerah penelitian. Pengidentifikasian alterasi hidrotermal dapat dilakukan dengan melakukan survey langsung ke daerah manifestasi, namun itu akan memakan waktu, sehingga untuk memaksimalkan waktu, dilakukan pemetaan dengan memanfaatkan pengaplikasian dari citra landsat 8 OLI/TIRS sehingga tidak perlu pergi ke daerah penelitian untuk melakukan pemetaan.

\subsection{Konsep Alterasi Hidrotermal}

Alterasi batuan merupakan suatu proses yang sangat kompleks yang melibatkan perubahan pada 
mineralogi, kimiawi, dan tekstur yang disebabkan oleh interaksi dari fluida panas dengan batuan yang dilaluinya (wall rock) di bawah kondisi evolusi fisiokimia. Pada proses alterasi, fluida hidrotermal mengambil kation dan anion dari batuan untuk membentuk mineral sekunder yang lebih stabil pada kondisi tersebut (Pirajno, 2009). Pada proses alterasi pula terjadi bentuk metasomatisme, yaitu adanya pertukaran dari komponen kimiawi berupa cairan dengan batuan dinding. Interaksi yang terjadi antara fluida hidrotermal dengan batuan yang dilewatinya (batuan dinding) akan menyebabkan mineral-mineral primer berubah menjadi mineral ubahan (mineral alterasi) maupun fluida itu sendiri. Terdapat beberapa faktor yang mempengaruhi proses alterasi antara lain: 1) Kondisi alami dari batuan dinding, 2) Komposisi fluida dan 3) Konsentrasi, aktivitas, serta potensi kimiawi dari komponen fluida. Kehadiran alterasi dalam suatu sistem panas bumi dapat hadir dalam tiga bentuk (Browne, 1998; Utami, 2015), yaitu pergantian mineral (replacement), pengendapan langsung (direct deposition), dan pencucian (leaching).

Alterasi berupa pergantian mineral terjadi ketika mineral primer mengalami perubahan menjadi mineral sekunder yang lebih stabil di kondisi tertentu pada lingkungan sistem panas bumi. Untuk membuat mineral tersebut lebih stabil, maka akan terjadi proses pergantian mineral primer menjadi mineral sekunder. Proses replacement sangat dipengaruhi oleh sifat batuan reservoar tersebut, utamanya sifat fisiknya, seperti permeabilitas, karena permeabilitas yang besar memberikan kesempatan kepada fluida hidrotermal untuk menghasilkan intensitas alterasi yang semakin kuat, dan sebaliknya (Nicholson, 1993). Alterasi yang terjadi karena pengendapan mineral umumnya terjadi di daerah yang memiliki manifestasi dari sistem panas bumi. Pengendapan mineral ini terjadi dikarenakan adanya ruang yang dapat berupa sesar, kekar, ketidakselarasan, lubang, pori, ataupun rekahan sehingga mineral hidrotermal dapat masuk dan mengendap. Pengendapan ini terjadi saat ada fluida hidrotermal yang mengandung mineral terlarut masuk ke dalam ruang tersebut dan kemudian mengalami penurunan suhu yang mengakibatkan solubilitas fluida turun sehingga mengendapkan mineral, seperti kuarsa atau kalsit (Nicholson, 1993). Pencucian atau leaching merupakan proses pelarutan batuan / mineral pada batuan oleh fluida hidrotermal yang biasanya bersifat asam, seperti H2S. Pada sistem geotermal, fluida asam yang mencuci batuan merupakan fluida yang berasal dari proses kondensasi fase uap (Nicholson, 1993), yang kemudian bercampur dengan air meteorik dan mengalami oksidasi yang menghasilkan sulfat . Kenampakan umum yang dijumpai pada batuan yang mengalami pencucian ialah pada tubuh batuan yang terdapat rongga, terutama di bagian fenokris batuan yang hilang akibat proses pencucian.

\subsection{Mineral Produk Alterasi Hidrotermal}

Proses alterasi hidrotermal adalah proses yang mengubah mineral primer menjadi mineral sekunder yang lebih stabil di kondisi tertentu (Pirajno, 2009). Produk hasil erupsi gunung api yang telah berumur Tersier - Kuarter biasanya mendominasi batuan dan mineral yang ada pada lapangan panas bumi.(Wohletz dan Heiken, 1992).

Pada proses alterasi hidrotermal, terjadi reaksi antara fluida geotermal dengan batuan pada kondisi $\mathrm{pH}$ dan suhu yang berbeda, sehingga akan menyebabkan perubahan mineral primer menjadi mineral sekunder yang lebih stabil di keadaan tertentu. Beberapa mineral primer yang umum dijumpai pada suatu daerah yang tersusun atas batuan vulkanik dan mineral alterasinya adalah (Lihat pada Tabel 1.) gelas vulkanik, Ilmenit, Magnetit, Olivin, Piroksen, Amfibol, Plagioklas, K Feldspar, dan Kuarsa, dengan mineral hasil alterasi hidrotermal yang dapat dijumpai antara lain Zeolit, Kristobalit, Kuarsa, Kalsit, Pirit, Hematit, Klorit, Epidot, Albit, Adularia, Illit, Sphene, dan lain-lain. (Wohletz dan Heiken, 1992; Lagat, 2009).

Lapangan geotermal dibagi ke dalam beberapa zona dengan penamaan yang menggunakan istilah fasies vulkanik, yaitu Central Zone, Proximal Zona, dan Distal Zone. Dimana central zone pada istilah fasies vulkanik ialah daerah puncak gunung api, proximal zone daerah dari tubuh gunung api, dan distal zone daerah berlereng landai dan dataran di sekitar tubuh gunung api (William dan McBirney, 1979 dalam Bronto, 2006).

Dalam menentukan persebaran mineral sekunder hasil alterasi hidrotermal, bahan yang digunakan adalah peta Geologi regional daerah Suoh, Lampung Barat berskala 1 : 250.000, citra Landsat 8 OLI/ TIRS, serta publikasi terkait mengenai kondisi geologi dari daerah penelitian.

Dalam penelitian ini, software yang digunakan dalam mengolah citra dan pembuatan peta adalah ArcGIS 10.3 dan Environtmental for Visualizing Images 5.3 (ENVI 5.3). Melalui software tersebut, dibuat berbagai kombinasi saluran RGB yang meliputi: 1) Citra komposit 432, 2) Citra komposit $567,3)$ Citra komposit 4/2, 6/7 dan 5, serta 4) Citra komposit 4/2, 6/7 dan 10. Untuk mendapatkan gambaran yang lebih jelas mengenai kondisi daerah penelitian dapat menggunakan saluran 8 pankromatik yang melalui proses penajaman dengan resolusi spasial $15 \times 15$ meter.

Selain dari pengamatan warna objek pada citra komposit yang menunjukkan keberadaan batuan teralterasi, metode lain yang digunakan adalah menggunakan density slicing. Density Slicing dilakukan dengan mengoreksi nilai piksel dari saluran yang akan dirasiokan, sehingga rentang nilai pikselnya menjadi 0 - 255. Selanjutnya, nilai Threshold Value dari nilai masing-masing rasio yang dihitung sehingga density slicing dapat dilakukan dengan menggunakan nilai dari rentang nilai piksel $\mathrm{TH}$ - 255 dari masing-masing rasio tersebut (Zhifang dkk, 2008). 
Threshold Values $=$ Mean $+\mathrm{n}$. St Deviasi

$* \mathrm{n}=1$ (confidence level : $92 \%$

2 (confidence level : $95 \%$ )

3 (confidence level : $98 \%$ )

Hasil akhir dari penelitian yang dilakukan akan ditampilkan dalam bentuk peta citra komposit warna RGB dan peta persebaran dari beberapa mineral alterasi.

\section{HASIL DAN PEMBAHASAN}

\subsection{Interpretasi Kondisi Geologi, Geomorfologi, serta Penutupan Lahan.}

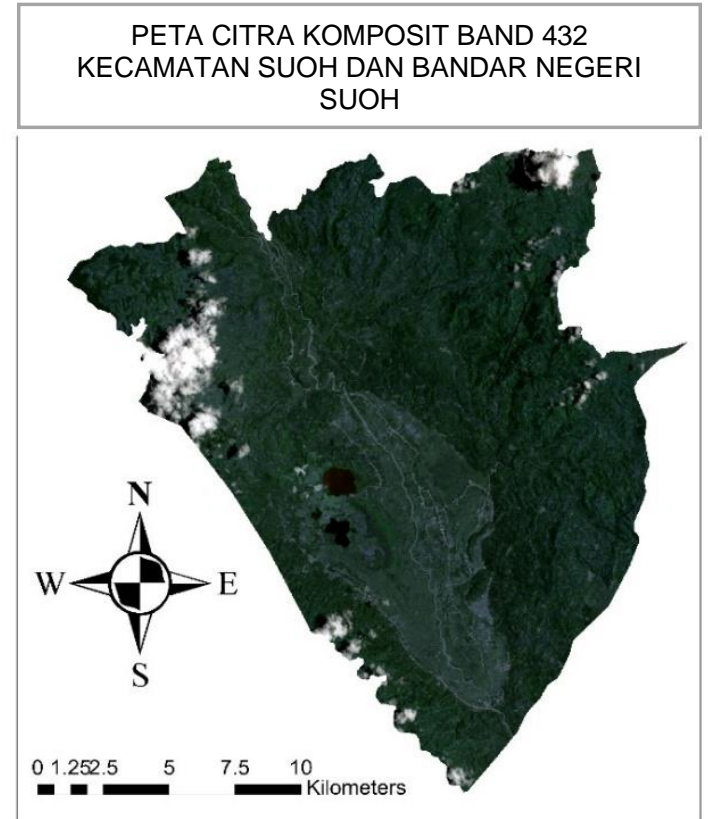

Gambar 1. Citra Komposit RGB 432 yang dapat memberikan gambaran mengenai kondisi geologi, geomorfologi, dan tutupan lahan daerah penelitian.

Pada citra komposit 432, dimana band 4 (0.636 - $0.636 \mu \mathrm{m}$ ) diposisikan pada band merah, band 3 $(0.533-0.590 \mu \mathrm{m})$ diposisikan pada band hijau dan band $2(0.452-0.512 \mu \mathrm{m})$ diposisikan pada band biru. Dengan menggunakan kombinasi ketiga band tersebut, kita dapat melihat kondisi geologi dan geomorfologi daerah penelitian secara regional, dimana daerah penelitian termasuk ke dalam bukit barisan selatan. Dengan menggunakan komposit RGB 432 juga dapat ditemukan beberapa kenampakan fitur geologi, seperti batuan kristalin yang ditandai dengan tekstur kasar sedangkan batuan non kristalin atau batuan sedimen terdeteksi dengan tekstur yang lebih halus.

Pada citra komposit 567, dimana band 5 (0.851 - $0.879 \mu \mathrm{m}$ ) diposisikan pada band merah, band 6 $(1.566-1.651 \mu \mathrm{m})$ diposisikan pada band hijau dan band 7 (2.107 - $2.294 \mu \mathrm{m})$ diposisikan pada band biru. Dengan kombinasi dari ketiga band tersebut, kita dapat melihat informasi geologi yang lebih baik dibandingkan dengan menggunakan komposit citra dengan warna natural 432. Dapat diamati didaerah penelitian terdapat baruan dengan tekstur yang lebih kasar dan lebih halus, tekstur kasar ini dijumpai pada daerah perbukitan serta daerah dengan ketinggian yang lebih rendah dilihat mempunyai batuan yang bertekstur lebih halus.

Dari hasil komposit RGB 567 ditemukan beberapa kelurusan yang memiliki orientasi Utara Timur Laut - Selatan Barat Daya, Utara - Selatan.

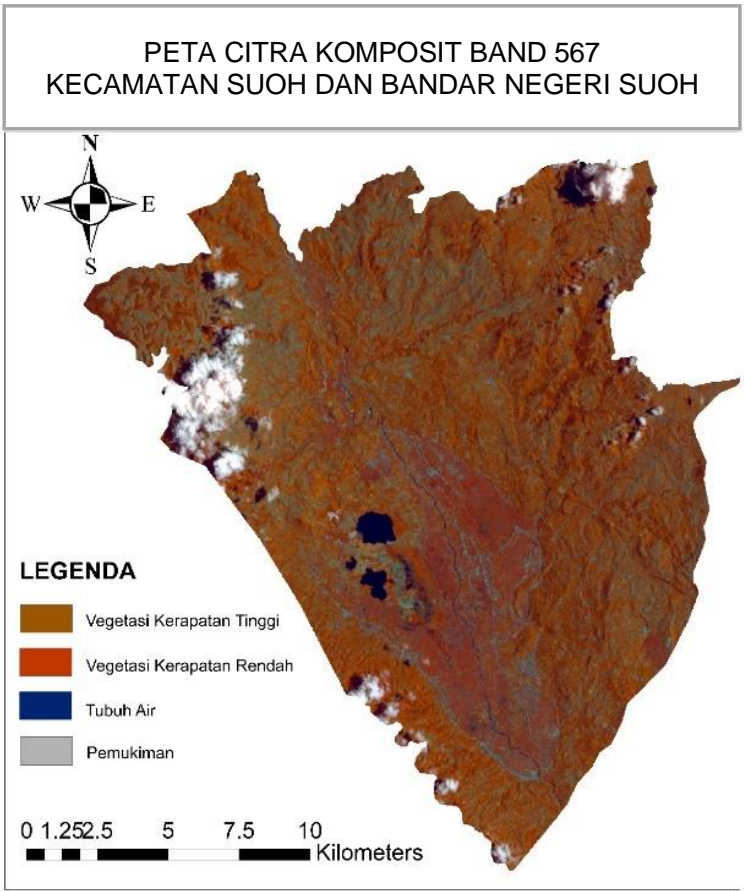

Gambar 2. Citra Komposit RGB 567 yang memberikan gambaran kodisi geologi dengan lebih mendetail.

Selain itu kondisi vegetasi juga dapat dideteksi dengan kombinasi band RGB 567 ini, dimana hampir seluruh daerah penelitian tertutupi oleh vegetasi yang ditandai dengan warna merah kecoklatan. Terlihat bahwa pada daerah penelitian,vegetasi tumbuh dengan baik pada daerah perbukitan namun pada pemukiman kontras sudah berkurang yang menandakan banyaknya aktivitas manusia. Daerah dekat pemukiman yang memiliki warna merah mendominasi menandakan bahwa lahan tersebut ditanami padi oleh masyarakat setempat.

Pada citra komposit 10117, dimana band 10 dan 11 merupakan band inframerah. Band 10 (10.60 $11.19 \mu \mathrm{m})$ diposisikan pada band merah, band 11 (0 11.50 - $12.51 \mu \mathrm{m}$ ) diposisikan pada band hijau dan band $7(2.107-2.294 \mu \mathrm{m})$ diposisikan pada band biru. 


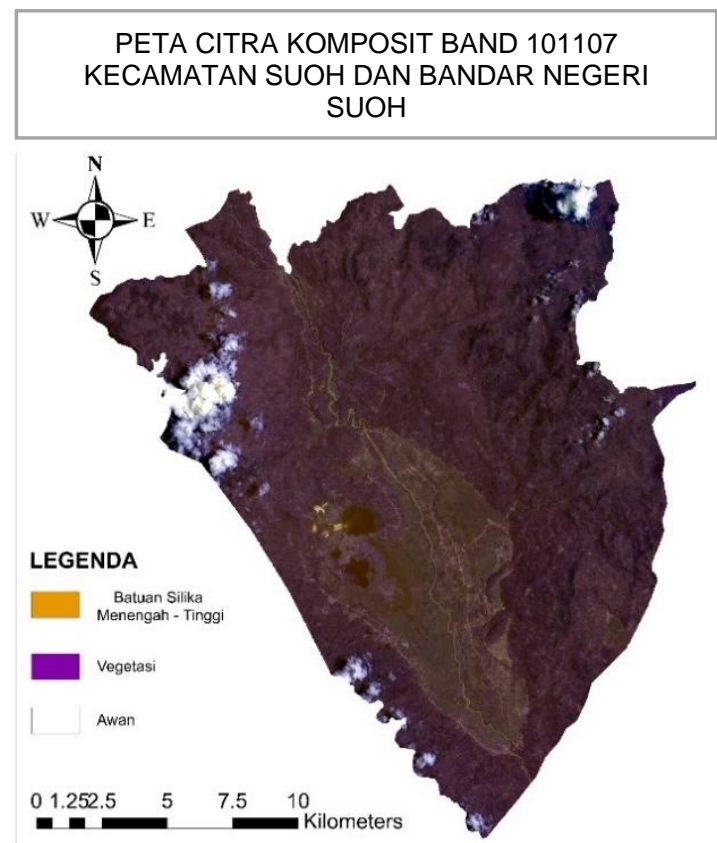

Gambar 3. Citra Komposit RGB 101107 yang memberikan informasi mengenai kondisi kandungan silika pada batuan atau keberadaan mineral silika yang ada di daerah penelitian. Kenampakan citra dengan warna kuning kebiruan memberikan indikasi adanya kandungan silika.

Dengan kombinasi dari ketiga band tersebut, kita dapat melihat informasi mengenai kandungan silika pada batuan yang ada di daerah penelitian secara regional, hal ini dikarenakan reflektansinya yang kuat dengan panjang gelombang $8.50-9.30$ dan 10.30 - 11.70 (Pour dan Hashim, 2014). Secara regional, batuan didaerah penelitian memiliki kandungan silika dengan konsentrasi tinggi berada di daerah sungai dan tertingginya berada pada titik yang menunjukkan manifestasi panas bumi di dekat danau Lebar dan danau Asam.

\subsection{Kondisi Alterasi Hidrotermal}

Alterasi hidrotermal dapat dilihat dengan melakukan beberapa kombinasi band yang mempunyai nilai reflektansi tinggi terhadap mineral alterasi hidrotermal. Band $4(0.636-0.673 \mu \mathrm{m})$, band $2(0.452-0.512 \mu \mathrm{m})$, band $5(0.851-0.879$ $\mu \mathrm{m})$, band $6(1.566-1.651 \mu \mathrm{m})$, band 7 (2.107 $2.294 \mu \mathrm{m})$, dan band $10(10.60-11.19 \mu \mathrm{m})$ dapat digunakan untuk melakukan pemetaan terhadap mineral yang teralterasi hidrotermal (Pour dan Hashim, 2014). Pemetaan sebaran mineral ini dilakukan dengan menggunakan metode rasio. Metode rasio dilakukan dengan membagi nilai dari panjang gelombang suatu band dengan band lainnya untuk mendapatkan kenampakan suatu objek tertentu. Metode ini dilakukan terhadap beberapa band, seperti band 4 yang dirasiokan dengan ban 2, band 6 dirasiokan dengan band 7 yang menghasilkan nilai dari reflektansi mineral alterasi hidrotermal di permukaan.

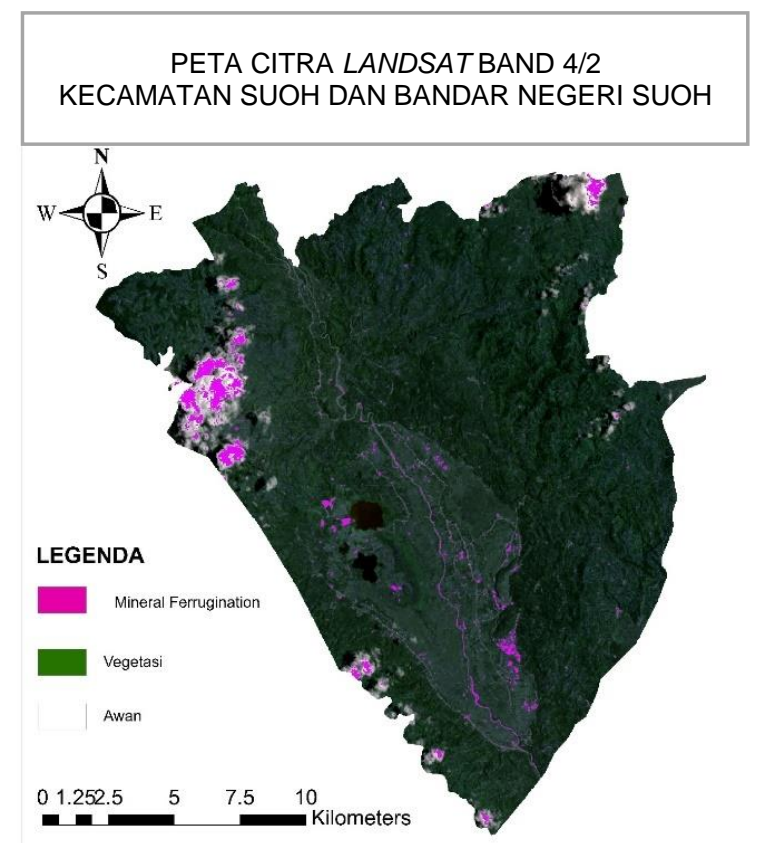

Gambar 4. Citra Komposit band rasio $4 / 2$ yang menampilkan informasi mengenai persebaran mineral Ferrugination (liomit) di daerah penelitian. Tampak bahwa mineral tersebar di sepanjang sungai Semangka dan daerah manifestasi hidrotermal.

Pada kombinasi band 4/2,6/7, dan 10, terlihat keberadaan mineral hasil alterasi yang terekam sebagai warna merah muda dan kuning, selain itu juga pemukiman terlihat sebagai warna ungu serta vegetasi yang terlihat sebagai warna hijau dan biru.

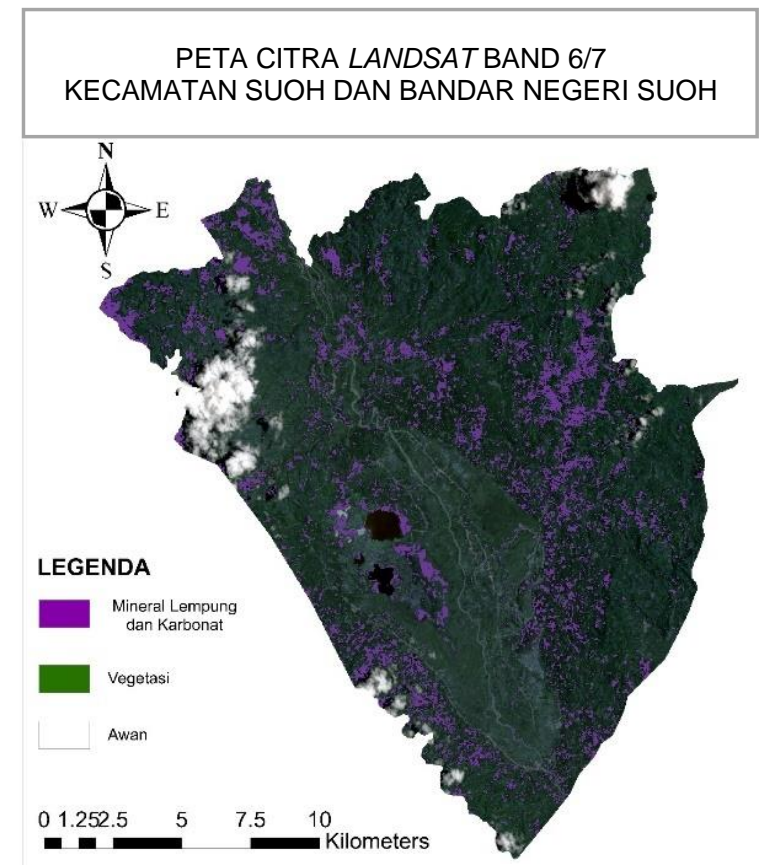

Gambar 5. Citra Komposit band rasio 6/7 yang menampilkan informasi persebaran mineral lempung hidroksida dan karbonat pada daerah penelitian. terlihat mineral tersebut tersebar di 
daerah perbukitan dan daerah manifestasi panas bumi.

Sementara pada kombinasi band 4/2, 6/7, dan 5, keberadaan mineral alterasi hidrotermal terekam sebagai warna kuning, drainase dan permukan berwarna merah serta vegetasi berwarna biru kehijauan hingga hijau.

\subsection{Persebaran Mineral alterasi}

\subsubsection{Metode Citra Komposit}

Dengan menggunakan komposit citra 4 band 4/2, 6/7, 5 dan 10, dapat dilihat penyebaran mineral alterasi mineral hidrotermal pada daerah penelitian.

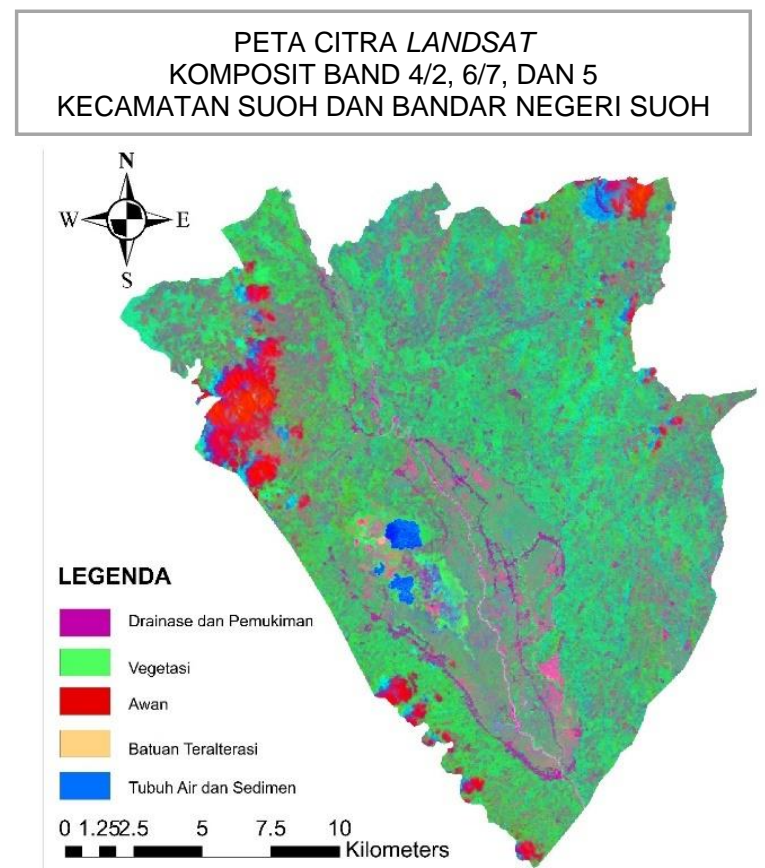

Gambar 6. Citra Komposit RGB band rasio 4/2, 6/7, dan 10 yang dapat memberikan informasi utama mengenai mineral alterasi hidrotermal dengan warna cream. Daerah alterasi berada di dekat danau yang merupakan manifestasi panas bumi.

Mineral ini dikenali dengan kenampakan warna kuning hingga oranye pada komposit citra RGB 4/2, $6 / 7$, dan 5, serta berwarna merah muda pada komposit RGB 4/2, 6/7, dan 10 (Pour dan Hashim, 2014). Persebaran mineral alterasi ini banyak ditemukan sepanjang sungai dan daerah dekat danau yang merupakan manifestasi panas bumi di daerah penelitian. Dari komposit citra yang telah dilakukan, luas daerah batuan teralterasi pada daaerah penelitian mencapai $223 \mathrm{Ha}$.

\section{3. 2. Metode Density Slicing}

Metode ini merupakan metode yang dilakukan dengan melakukan pengambilan sejumlah nilai piksel yang merepresentasikan mineral di permukaan berdasarkan pantulannya. Pada penelitian ini, digunakan citra rasio $4 / 2,6 / 7$, dan $5 / 6$ yang menunjukan keberadaan dari mineral oksida dan hidroksida dari besi, mineral lempung dan mineral karbonat serta mineral ferromagnesium (Pour dan Hashim, 2014).

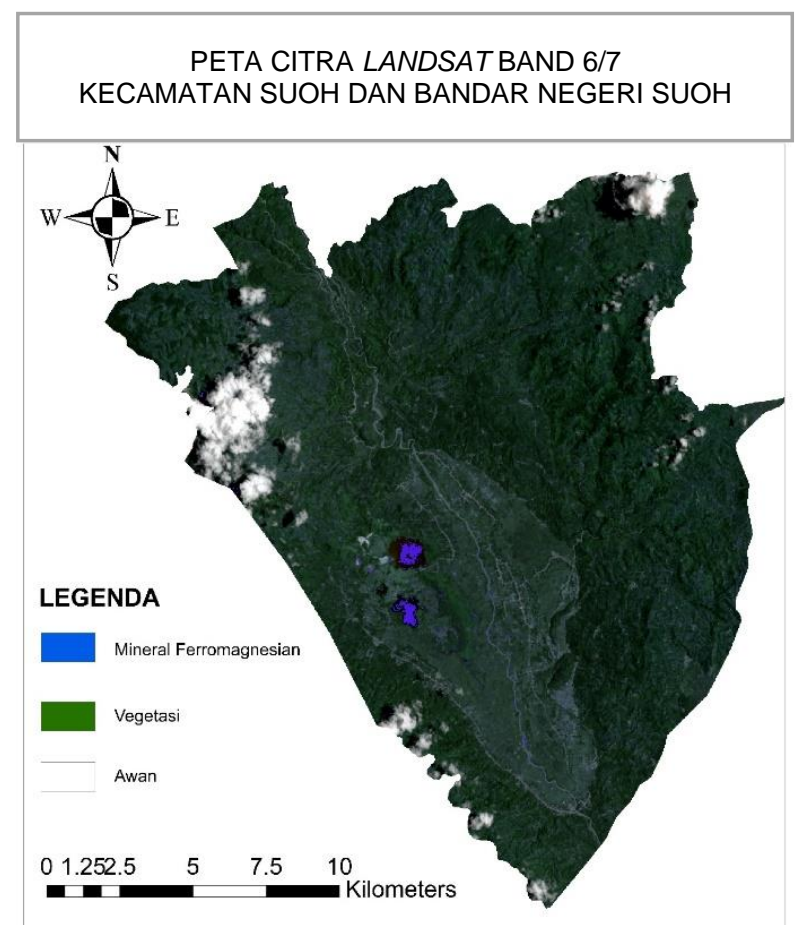

Gambar 7. Citra Komposit band rasio $5 / 6$ yang menampilkan informasi persebaran mineral Ferromagnesian pada daerah penelitian. terlihat mineral tersebut berada di dua danau Lebar dan danau Asam

- Mineral Ferrugination (Iron Oxides dan Hydroxides).

Dengan menggunakan rasio $4 / 2$ pada rentang pixel 200,80 - 255 kita dapat memetakan persebaran mineral alterasi Ferrugination (Gambar 4). Persebaran mineral kelompok ferrugnation ini berada pada sepanjang sungai dan daerah manifestasi panas bumi di dekat danau Lebar dan danau Asam. Terdapat gangguan dalam pembacaan saat mencoba mengidentifikasi kelompok mineral Ferrugunation ini diakarenakan awan tebal juga terdeteksi sebagai mineral

- Mineral Ferromagnesian

Mineral kelompok Ferromagnesian yang merupakan salah satu kelompok mineral alterasi hidrotermal ini dapat terlihat dengan melakukan density slicing pada rasio $5 / 6$ dengan rentang nilai pixel 195,43 - 255 . Persebaran mineral kelompok ini terkonsentrasi pada kedua danau yang berada di kecaatan suoh. Tetapi, dengan menggunakan metode ini, perbedaan antara mineral Ferromagnesian primer dan sekunder yang merupakan hasil alterasi tidak dapat dibedakan

- Mineral Lempung dan Karbonat Mineral alterasi kelompok lempung dan karbodat terpetakan persebarannya DOI: https://doi.org/10.23960/igrs.2020.v1i2.41 
dengan melakukan density slicing pada rasio $6 / 7$ di rentang pixel mulai dari 208,45 - 255 (Gambar 5). Perbesaran mineral ini terlihat menyebar di daerah perbukitan serta di daerah manifestasi panas bumi dekat danau Lebar dan danau Asam.

\section{KESIMPULAN}

Berdasarkan hasil penelitian di atas didapatkan kesimpulan bahwa Citra Landsat 8 OLI/TIRS terbukti dapat memetakan daerah alterasi hidrotermal secara regional yang dapat dilakukan dengan memproses beberapa band yang mempunyai rentang pixel yang merepresentasikan mineral alterasi mineral hidrotermal pada daerah penelitian. Mineral atlerasi tersebut terdeteksi dengan warna kuning - orange pada citra komposit 4/2, 6/7, 5 dan 10, dengan menggunakan metode density slicing. Kemampuan citra Landsat ini masih terbatas diakrenakan beberapa masalah pembacaan seperti terganggunya warna citra komposit oleh awan, atau terbacanya awan tebal sebagai mineral ferrumagnition pada rasio band $4 / 2$.

Pemetaan awal untuk mengetahui persebaran dari mineral Alterasi Hidrotermal ini dapat dilakukan dengan menggunakan citra Landsat $8 \mathrm{OLI} / \mathrm{TIRS}$ dalam mengeksplorasi potensi geothermal, mineral, ataupun lainnya. Namun, faktor awan serta vegetasi harus dipertimbangkan dalam pemilihan citra yang digunakan.

\section{UCAPAN TERIMA KASIH}

Terima kasih kami ucapkan kepada pihak-pihak yang telah memberikan izin untuk dapat mengakses data-data yang kami perlukan, USGS serta rekanrekan lainnya yang membantu dalam pengolahan dan pengerjaan paper ini.

\section{DAFTAR PUSTAKA}

Barber, A. J., Crow, M. J., \& Milsom, J. S. (2005). Sumatra: geology, resources and tectonic evolution vol. 31. London UK: Geological Society of London.

Browne, P. R. L. (1970). Hydrothermal Minerals as an Aid in Investigating Geothermal Field. Journal of Geothermics, 2(1), 564-570.

Browne, P. R. L. (1998). Hydrothermal Alteration. Geothermal Institute: The University of Auckland.

Cahyati. (2018). Alterasi Hidrothermal Dan Tempreratur Bawah Permukaan Sumur $\mathrm{X}$ Lapangan Panasbumi Patuha. Padjadjaran Geoscience Journal, 2(6), 514-515.

Fossen, H. (2010). Structural Geology. Cambridge University Press.

Humam, A., Hidayat, M., Nurrochman, A., Anestatia, A. I., Yuliantina, A., \& Aji, S. P. (2020). Identifikasi Daerah Kerawanan Kebakaran Hutan dan Lahan Menggunakan Sistem informasi Geografis dan Penginderaan Jauh di Kawasan Tanjung
Jabung Barat Provinsi Jambi. Jurnal Geosains Dan Remote Sensing, 1(1), 32-42.

lqbal, M., \& Juliarka, B. R. (2019). Analisis Kerapatan Kelurusan (Lineament Density) Sebagai Indikator Tingkat Permeabilitas di Lapangan Panasbumi Suoh-Sekincau, Lampung. Jurnal of Science and Applicative Tecnology, 3(2), 61-67.

Hochstein, M. P., \& Sudarman, S. (2008). History of geothermal exploration inlndonesia from 1970 to 2000. Geothermics, 37(3), 220-266.

PSDMBP. (2017). Potensi Panas Bumi Indonesia. Jakarta: Direktorat Panas Bumi, Direktorat Jenderal Energi Baru, Terbarukan dan Konservasi Energi, Kementerian Energi dan Sumber Daya Mineral.

Putra, I. D., Nasution, R. A. F., \& Harijoko, A. (2017). Aplikasi Landsat 8 OLI/TIRS dalam Mengidentifikasi Alterasi Hidrotermal Skala Regional: Studi Kasus Daerah Rejang Lebong dan Sekitarnya, Provinsi Bengkulu. Proceeding Seminar Nasional Kebumian ke10, Yogyakarta.

Gupta, R. P. (2018). Remote Sensing Geology 3 ed. Berlin Heidelberg: Springer Varlage.

Rahayu, R., \& Candra, D. S. (2014). Koreksi Radiometrik Citra Landsat-8 Kanal Multispektral Menggunakan Top of Atmosphere (ToA) Untuk Mendukung Klasifikasi Penutup Lahan. Prosiding Seminar Nasional Penginderaan Jauh, LAPAN 762768.

Sabins, F. F. (1999). Remote Sensing for Mineral Exploration. Ore Geology Reviews. 14, 157183.

Siregar, D. A., \& Yudhicara. (2019). Pentarikhan Radiokarbon Dalam Penentuan Umur Aktivitas Sesar Sumatera Di Liwa, Lampung. Jurnal Lingkungan dan Bencana Geologi, 8(1), 13-17.

Sitanggang, G. (2010). Kajian Pemanfaatan Satelit Mas Depan: Sistem Penginderaan Jauh Satelit LDCM (Lansat-8). Berita Dirgantara. 11(2), 47-58.

Soehaimi, A., Marjiyono, K., \& Muslim, D. (2013). The Sumatran Active Fault and Its Paleosesmicity. Aachen: 4th International INQUA Meetign on Paleoseismology, Active Tectonics and Archeoseismology (PATA).

Amin, T. C., Sidarto, S., \& Gunawan, W. (1993). Peta Geologi Lembar Kotaagung, Sumatera skala 1:250.000. Bandung: Pusat Penelitian dan Pengembangan Geologi.

Utami, P. (2011). Hydrothermal Alteration and the Evolution of the Lahendong Geothermal System, North Sulawesi, Indonesia. Thesis, The University of Auckland.

Utami, P., Widarto, D. S., Atmojo, J. P., Kamah, Y., Browne P. R. L., \& Warmada, I. W. (2015). Hydrothermal Alteration and Evolution of Lahendong Geothermal System, North Sulawesi, Proceeding of World Geothermal Congress. 
Zuhannisa, S., Cahyono, B.E., \& Priyantari, N. (2019). Pemetaan Citra Lansat 8 Untuk Pemetaan Potensial Mineralisasi Emas di
Kabupaten Tapanuli Selatan, Sumatera Utara. Indonesian Journal of Appliead Physics. 9(1), 3-4. 